\title{
Mechanical characterization of rock splitting planes in granitic rocks
}

\author{
L.C.R. Almeida ${ }^{\mathrm{a}, 1}$, E.do A. Vargas $\mathrm{Jr}^{\mathrm{b}, \mathrm{c}, *}$, R.P. de Figueiredo ${ }^{\mathrm{d}}$ \\ ${ }^{a}$ Repsol-YPF, Madrid, Spain \\ ${ }^{\mathrm{b}}$ Civil Engineering Department, Catholic University of Rio de Janeiro, Brazil \\ ${ }^{\mathrm{c}}$ Geology Department, Federal University of Rio de Janeiro, Brazil \\ ${ }^{\mathrm{d}}$ Mining Engineering Department, Federal University of Ouro Preto, Ouro Preto, Brazil
}

Accepted 15 March 2006

Available online 9 June 2006

\section{Introduction}

Granitic rocks can in general be easily split through three mutually orthogonal surfaces, empirically identified in the field $[1,2]$. The knowledge of these splitting planes is widely used to improve the efficiency of stone cutting (quarrying). For example, it can be useful for the stabilization of granitic boulders in slopes in conjunction with controlled blasting and fragmentation. Many stabilization projects, based on controlled blasting in slopes of Rio de Janeiro have been reported recently $[3,4]$. It has been found that this method represents a good alternative to avoid the high costs of conventional civil engineering techniques currently adopted for stabilization works.

Although granitic rocks are regarded as a homogeneous isotropic material, splitting planes are assumed to correspond to physical anisotropies related to microcracks that seem to be oriented due to magmatic flow. An association between microcrack distribution patterns and granitic rock splitting planes have been proposed $[5,14,15,20]$. Nevertheless, the establishment of such an association, even using a microscope, remains rather difficult. Correlations of granite anisotropies with different mechanical properties such as tensile/compressive strength, Young's modulus and acoustic wave velocity have been proposed with some success $[13,15,18,19]$.

The present paper reports results obtained in a research project which investigates anisotropies in relevant mechan-

\footnotetext{
*Corresponding author. Civil Engineering Department, Catholic University of Rio de Janeiro, Brazil. Tel.: + 552131141188 ; fax: +552131141195 .

E-mail address: vargas@civ.puc-rio.br (E.A. Vargas Jr).

${ }^{1}$ Formerly at the Geology Department, Federal University of Rio de Janeiro, Brazil.
}

ical properties of granitic rocks due to the existence of such splitting planes. In particular, the paper focuses on measurements of the fracture toughness $\left(K_{\mathrm{IC}}\right)$ along the splitting plane directions of samples of granitic rocks of Rio de Janeiro. $K_{\mathrm{IC}}$ is a measure of the fracture energy required to create a new surface into the material under mode I loading [12]. It can also be regarded as a measure of the capacity of the material to resist growth of a preexisting crack under tensile conditions and could in principle quantify differences in the resistance to cutting along the splitting planes. Furthermore, it is believed [14] that fracture toughness can be more easily related to the prediction, through analytical/numerical models, of the cutting processes in rocks as compared to other mechanical properties such as tensile/compressive strength, Young's modulus and acoustic wave velocity focused in previous works $[13,15,18,19]$.

For that matter, tests were carried out on samples of two granites of Rio de Janeiro especially prepared in order to determine their fracture toughness under mode I condition along their splitting planes. The test results are presented and discussed. Subsequently, the test results are used in conjunction with an analytical estimate of the required borehole spacing for block fragmentation/cutting under static or quasi-static conditions. The application highlights the practical impact of the anisotropy in fracture toughness of such materials.

\section{Characterization of splitting planes of granitic rocks}

Although splitting planes characterization through microscope is sometimes difficult, (more so for coarse grained granites), field observations indicate that these planes can be identified macroscopically through the 
tracing of magmatic flow foliation. The practical experience associated to quarrying activities shows that it is easier to split the rock along these planes. All granitic rocks seem to possess three sets of nearly orthogonal planes of symmetry $[13-15,20]$. Furthermore, experience shows that each of the three perpendicular planes has a different splitting resistance. The most resistant is the hardway (or divider) plane, the intermediate resistant plane is the grain (or arrester) and the weakest one is the rift (or short transverse) plane. Usually the quarry workers search, by experience and observation, for the rift plane in order to facilitate their task of splitting granitic rocks (Fig. 1).

The rift in granites is recognized as a foliation, unclear in some cases, along which the granite splits more easily than in any other direction. Although the causes of rift structures and the relative time of their formation are not yet known, it is well-known that granitic rocks are brittle materials and often contain small defects which are preferentially oriented along three mutually perpendicular planes. Researchers have tried to correlate the splitting plane directions with directional microstructural features of the rock. Kudo et al. [13] made a comprehensive investigation, using thin sections, of possible relationships between microcrack orientations and the splitting plane directions. They found strong orientations of open and healed microcracks with all the three splitting planes. The same tendencies were found by Chen et al. [5] and more recently by Takemura et al. [18], distinguishing between inter/intracrystalline and grain boundary cracks. However in all these works, no evidence of preferred orientation and density of microcracks along the rift plane in relation to the other planes was found. Johnson [20]. however, using a quantitative analysis of thin sections of granites (using stereonet plot counting techniques of poles), was able to show that most of the microcracks were parallel or subparallel to the rift as shown in Fig. 2. A small number of cracks was aligned with the hardway and an intermediary number parallel to the grain. Another microstructural feature of interest is grain size. Nasseri et al. [14] established a relationship between fracture toughness and grain size for granites although not explicitly relating the obtained values to splitting plane directions.

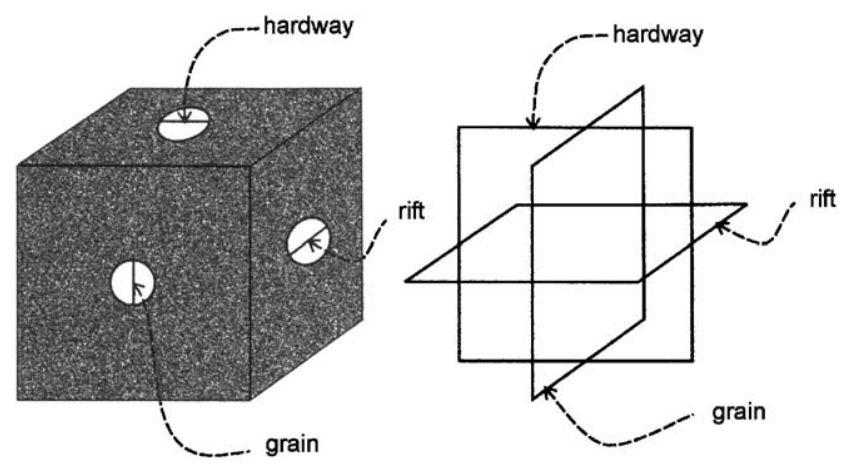

Fig. 1. Orientation of splitting planes.

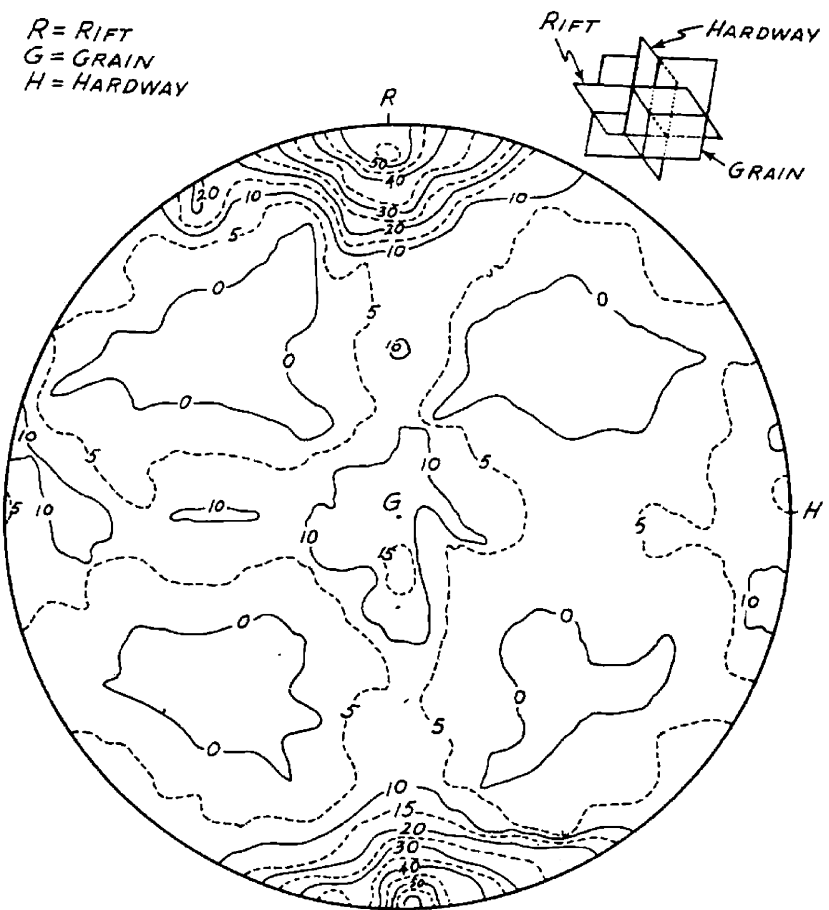

Fig. 2. Stereonet plot of poles of microcracks in a sample of Chelmsford granite. Most of the microcracks are nearly parallel to the rift (done by S.D. Peng and reported by Johnson [20]).

Although most of the surveyed literature indicates the existence of relationships between splitting plane directions and directional micro-structural texture characteristics in granitic rocks, this topic remains somewhat controversial and in need of further research.

\section{Granites tested}

Two types of granitic rocks commonly found in Rio de Janeiro were investigated in this study, Utinga and Favela granites (Fig. 3). These granites were defined as granitic intrusions into gneissic rocks from Proterozoic age. These post-tectonic granitoids are I-type (Hornblende)-biotite granitoids, fine to medium grained, equigranular to porphyritic, locally displaying preserved magmatic flow foliation. They occur as tabular bodies, dikes, stocks and small batholiths crosscutting the country rocks [6]. Utinga is a medium to coarse granite while Favela is fine to medium granite. Macroscopically, both rocks exhibit the mutually orthogonal splitting planes. Samples were collected from oriented cores taken from quarried stones with clear identification of their splitting planes. In the quarry, the most important splitting plane to identify is the rift plane, which helps to trace the divider and arrester planes.

\section{Testing methodology}

In order to determine fracture toughness under mode I along the splitting planes, the ISRM suggested methodology was used [7]. The methodology proposes the use of a 


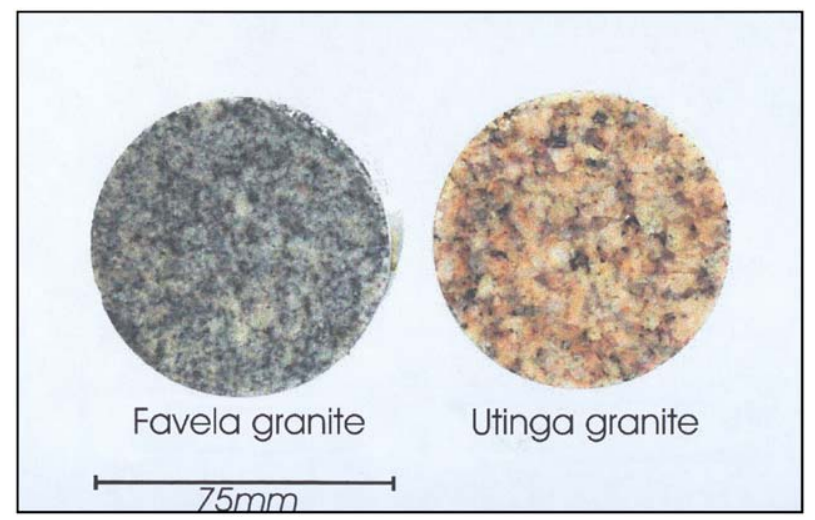

Fig. 3. Utinga and Favela granites.

cracked Chevron notched Brazilian disc (CCNBD) specimen, one which has a notch cut along the core diameter. As illustrated in Figs. 1 and 4, the fracture toughness tests were conducted in a way that splitting plane orientation was coincident with the loading under mode-I type. Fig. 1, in particular, illustrates how the sample notches were oriented in relation to the splitting plane directions. The stress intensity factor $K_{\mathrm{IC}}$ was determined by using Eq. (1) as suggested by the ISRM methodology [7]:

$K_{\mathrm{IC}}=\left(\frac{P_{\max }}{B \sqrt{D}}\right) Y_{\min }^{*}$

where $P_{\max }$ is the peak load attained in the test, $B=30 \mathrm{~mm}$ is the thickness of the specimen, $D=75 \mathrm{~mm}$ is the diameter of the specimen and $Y_{\min }^{*}=0.84$ is the critical dimensionless stress intensity value determined by the specimen geometry used in this study. Recent papers $[8,9]$ reported on the accuracy of parameter $Y_{\min }^{*}$. However, the authors of the present paper believe that the possible variations of this parameter as reported in the above mentioned papers should not change the main conclusions of the work reported herein.

\section{Obtained results}

\subsection{Microscopic identification}

The macroscopic identification of splitting planes is relatively easy, but under microscope, its recognition becomes a rather difficult task. In many cases it is virtually impossible to identify the splitting planes through thin sections oriented parallel to each of the three orthogonal planes. This is particularly true for coarse-grained granites. The microscopic analysis of the fine-grained Favela granite on thin sections, oriented parallel to the rift plane, allowed the identification of igneous faces of minerals organized in preferential orientation. Nevertheless, for the coarsegrained Utinga granite, probably due to the grain size, no preferential mineral orientation was observed under microscope.

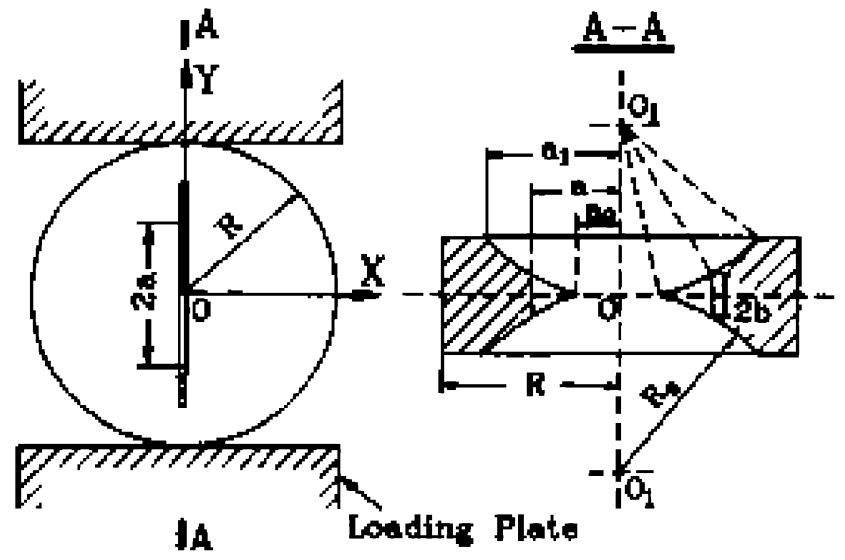

Fig. 4. CCNBD specimen geometry [7].
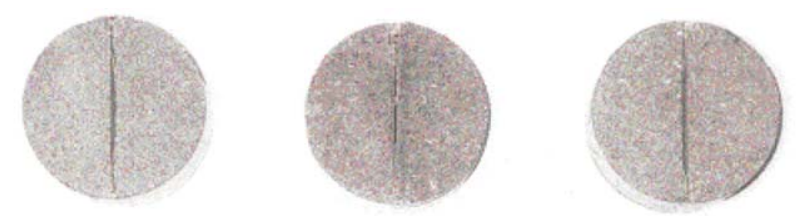

Favela Granite
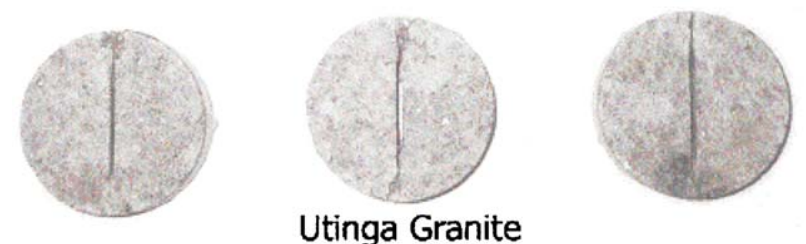

Fig. 5. Observed failure patterns in toughness tests of Favela and Utinga granites.

Despite the fact that the present study did not focus on microcrack analysis, the observation of thin sections of the Favela granite suggests that microcracks parallel to rift plane are mainly of the intercrystalline and grain boundary types. Similar results were reported by other authors [5]. For the others planes of Favela granite and Utinga granite no evident preferential orientation was observed.

\subsection{Tests}

Laboratory tests were carried out on the Rock Mechanics facilities of Petrobras's Research Center-CENPES in Rio de Janeiro. A total of 24 tests were performed under a servocontrolled MTS $10 \mathrm{GN} / \mathrm{m}$ stiffness, $2700 \mathrm{kN}$ capacity. Load control and load history were recorded up to the specimen's failure. The average rate of loading was $450 \mathrm{~N} / \mathrm{s}$ such that failure occurred within $20 \mathrm{~s}$ of initial loading.

Samples were tested under mode I type so that diametral loading applied during tests coincided with textural anisotropies (splitting planes) observed in the rocks under study. The observed failure pattern was consistent and coincident with the expected elasticity/failure theories of the adopted methodology (Fig. 5). The results obtained are shown in Figs. 6 and 7. 
In these figures, a visible dispersion in $K_{\mathrm{IC}}$ test results can be noticed. However, the scatter plot analysis for both types of granites shows that the energy required to create a new surface into these rocks is variable according to loading orientation. Average values of $K_{\mathrm{IC}}$ for the three loading orientations are shown in Tables 1 and 2. The tables also show coefficient of variation of the data obtained in the tests $(\mathrm{CV}=$ standard deviation/mean $)$ and the ratio between $K_{\mathrm{IC}}$ along a particular plane and

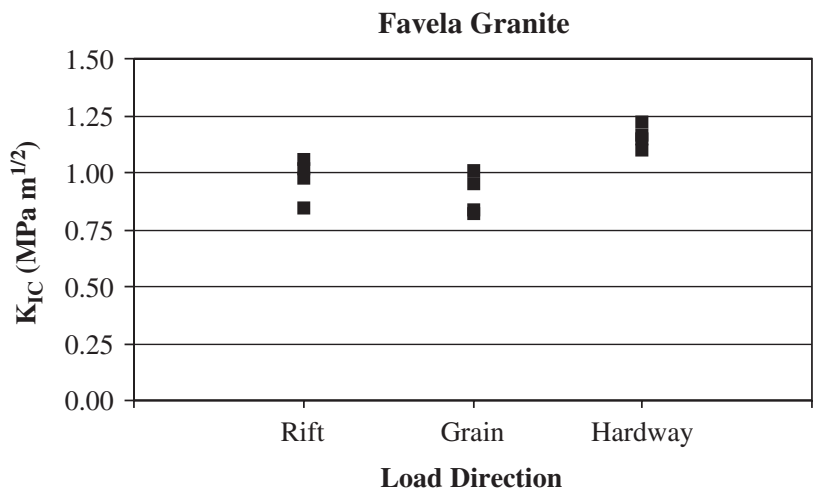

Fig. 6. $K_{\mathrm{IC}}$ test results for favela granite under mode I loading.

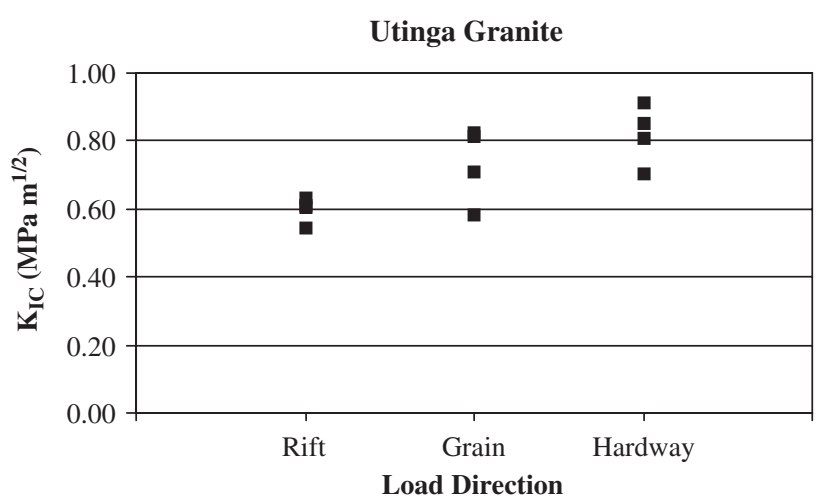

Fig. 7. $K_{\mathrm{IC}}$ test results for Utinga granite under mode I loading.
$K_{\text {IC }}$ determined at the hardway plane $\left(K_{\text {IChard }}\right)$. The values for the Favela granite shows a considerable reduction of $K_{\mathrm{IC}}$ between hardway and grain planes (around $22 \%$ ), on the other hand, between grain and rift planes an inversion is observed and mean value of $K_{\mathrm{IC}}$ for the rift plane is higher than mean values for the grain plane. These results show that not always the rift plane is the one of least resistance. A similar comparison for the Utinga granite shows a reduction of $10 \%$ between hardway and grain values of $K_{\mathrm{IC}}$ and $26 \%$ reduction between hardway and rift planes. Indeed, for both granites the plane most resistant to fracture propagation was the hardway plane. The values of $K_{\mathrm{IC}}$ and the dispersion of data obtained in all tests agreed with results obtained from similar (CCNBD) tests done in granite as reported in the literature [10,11], although in these references no mention was made in relation to the sample orientation in relation to splitting planes directions.

In addition, as also observed by other authors [12,14], the coarse-grained granite presented lower values of toughness than the fine grained one.

\section{A Simple analytical determination of rock cutting efficiency as related to toughness anisotropy}

The impact of knowing toughness anisotropy on the optimization of rock cutting/fragmentation processes will be demonstrated through the analysis of a simple problem geometry. The object of the exercise is the determination of the optimal spacing between aligned boreholes destined to be pressurized for fracture generation, propagation and coalescence in order to cut/fragment a rock block or a rock face. For that purpose, an expression of the stress intensity factor (SIF) derived by Koiter in 1959 (as appears in Sih [16]) is used. This expression corresponds to a line of collinear cracks of the same length $l$ in an infinite medium, regularly spaced of $S$ and subjected to a dipole of centrally located forces in the crack having intensity $F$ (Fig. 8). This solution can be considered appropriate to represent the borehole expansion from a non-penetrating agent such as

Table 1

Reduction of loading level required to failure samples of Favela granite

\begin{tabular}{llll}
\hline Loading orientation & $K_{\mathrm{IC}}$ mean $\left(\mathrm{MPa} m^{1 / 2}\right)$ & $\mathrm{CV}(\%)$ & $K_{\mathrm{IC}}$ mean $/ K_{\mathrm{IChard}}$ mean \\
\hline Rift plane & 0.97 & 8.42 & 0.839 \\
Grain plane & 0.90 & 8.61 & 0.778 \\
Hardway plane & 1.16 & 3.79 & 1 \\
\hline
\end{tabular}

Table 2

Reduction of loading level required to failure samples of Utinga granite

\begin{tabular}{llcl}
\hline Loading orientation & $K_{\mathrm{IC}}$ mean $\left(\mathrm{MPa} m^{1 / 2}\right)$ & $\mathrm{CV}(\%)$ & $K_{\mathrm{IC}}$ mean $/ K_{\mathrm{IChard}}$ mean \\
\hline Rift plane & 0.60 & 5.58 & 0.731 \\
Grain plane & 0.73 & 13.23 & 0.895 \\
Hardway plane & 0.82 & 9.44 & 1
\end{tabular}


an expansive paste. According to Ouchterlony [17], the analysis can be considered valid for both static and dynamic conditions.

The expansion pressure is only effective inside the boreholes, not exerting any pressure in the cracks. The corresponding value for $K_{\mathrm{I}}$ as given by Koiter's solution is:

$K_{\mathrm{I}}=\frac{\sqrt{2} F}{\sqrt{\pi S \sin (2 \pi l / S)}}$.

The larger the distance from the line of boreholes to a free face and the crack length being at least two times the radius of the borehole, the more valid are the hypotheses of the model expressed by Eq. (2). Under the latter condition, Ouchterlony [17] showed that it is valid to approximate the effect of pressurization along the whole of the circumference of the borehole by a force dipole centrally located in the crack which is $F=2 p r$, where $p$ is the pressure and $r$ is the borehole radius. In order to determine the optimal (maximum) spacing between boreholes, the above solution is made non-dimensional:

$$
\begin{aligned}
\bar{K}_{\mathrm{I}} & =\frac{K_{\mathrm{I}} \sqrt{\pi S}}{\sqrt{2} F} \\
& =\frac{1}{\sqrt{\sin (2 \pi l / S)}}=\frac{1}{\sqrt{\sin (2 \pi \lambda)}},
\end{aligned}
$$

where $\bar{K}_{\mathrm{I}}$ is the SIF in non-dimensional form and $\lambda=l / S$.

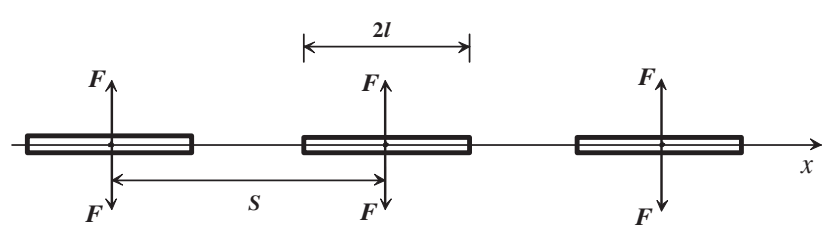

Fig. 8. Geometry of the problem of an infinite line of similar collinear cracks in an infinite medium (Koiter in 1959 as appears in Sih [16]).
The relationship $\bar{K}_{\mathrm{I}}$ versus $\lambda$ is plotted in Fig. 9. There, one notices that after an initial phase of stable propagation of the crack in which $\bar{K}_{\mathrm{I}}$ decreases, a minimum is found in $\lambda=0.25$, i.e. for $l=S / 4$. Subsequently, crack propagation becomes unstable with $\bar{K}_{\mathrm{I}}$ tending to infinity for $\lambda=0.5$ $(l=S / 2)$, when the neighboring cracks join, resulting in the desired cut of the rock.

The cut will be possible only if $K_{\mathrm{I}}$ corresponding to the minimum is greater than $K_{\mathrm{IC}}$. Therefore, the substitution of $l=S / 4$ in Eq. (2) gives

$K_{\mathrm{I}}^{\mathrm{MIN}}=\frac{\sqrt{2} F}{\sqrt{\pi S}} \geqslant K_{\mathrm{IC}}$.

Assuming the equality condition in Eq. (4) makes it possible to establish the maximum value of $S$ :

$S_{\mathrm{MAX}}=\frac{2}{\pi}\left(\frac{F}{K_{\mathrm{IC}}}\right)^{2}=C\left(1 / K_{\mathrm{IC}}\right)^{2}$

in which $C=2 F^{2} / \pi$ may be considered as a constant, independent from the rock properties.

One is able to notice from Eq. (5) that $S_{\text {MAX }}$ is proportional to $\left(1 / K_{\mathrm{IC}}\right)^{2}$. One can then quantitatively evaluate the effect of the toughness anisotropy into the efficiency of rock cutting. Taking for example Utinga granite and adopting average values for the different splitting planes one has

$K_{\mathrm{IC}}^{\text {rift }}=0.60 \mathrm{MPa}(m)^{1 / 2}$;

$K_{\mathrm{IC}}^{\text {grain }}=0.73 \mathrm{MPa}(m)^{1 / 2}$;

$K_{\mathrm{IC}}^{\text {hardway }}=0.82 \mathrm{MPa}(m)^{1 / 2}$.

Through Eq. (5), one can determine the maximum values of borehole spacing:

$$
\begin{gathered}
S_{\mathrm{MAX}}^{\text {rift }} \approx 2.78 C ; \\
S_{\mathrm{MAX}}^{\text {grain }} \approx 1.88 C ; \\
S_{\mathrm{MAX}}^{\text {hardway }} \approx 1.49 C ;
\end{gathered}
$$

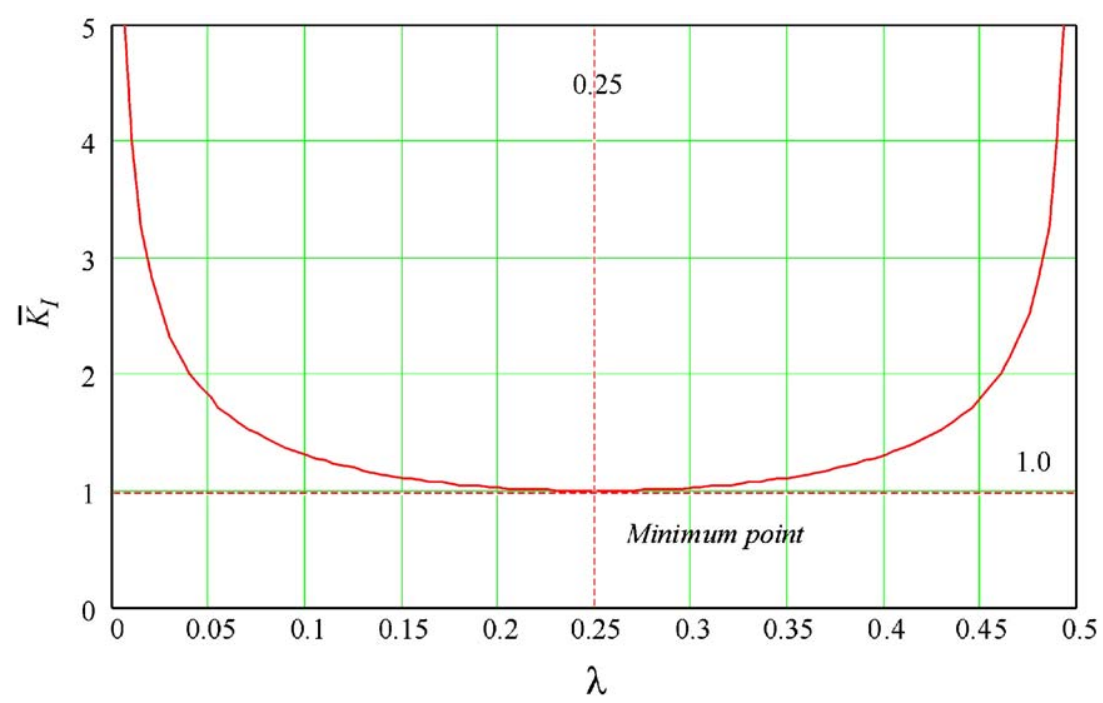

Fig. 9. $\bar{K}_{\mathrm{I}}$ versus $\lambda$ relationship showing the stable and unstable phases of crack propagation and the point of minimum for $\lambda=0.25$. 
and

$S_{\mathrm{MAX}}^{\mathrm{rift}} / S_{\mathrm{MAX}}^{\text {hardway }} \approx 1.87$

This result shows that a $87 \%$ larger borehole spacing can be used for a line of boreholes aligned with the rift plane as compared with the spacing of boreholes aligned with the hardway plane. A similar exercise using the toughness values for the Favela granite gives

$S_{\text {MAX }}^{\text {grain }} / S_{\text {MAX }}^{\text {hardway }} \approx 1.66$,

from which similar conclusions from Utinga granite can be drawn. It should be noted that an interaction of the borehole line with a free boundary (due to the proximity among them) would potentially increase these spacing differences [21].

\section{Conclusions}

Results of a research program aiming at the characterization of mechanical properties along splitting planes in granites were presented. Samples of coarse-grained and fined-grained granites from Rio de Janeiro were tested to determine fracture toughness under mode I conditions along possible splitting plane directions. These tests were performed on cracked Chevron notched Brazilian disc (CCNBD) specimens according to ISRM recommendations [7]. Although a certain dispersion in the results was encountered, a trend could be established in which the highest value of $K_{\mathrm{IC}}$ correspond to the hardway plane. In relation to the least resistant plane, in one granite (Favela) the grain plane was found to be the least resistant while in the other (Utinga) granite, the plane of least resistance was the rift. The obtained results coincide in general with longstanding, empirical observations of the work of hand and machine stone cutting and provide knowledge for a better understanding and design of such activities. A possible explanation for the encountered anisotropy in toughness of granitic rocks could be related to the fracture process zone (FPZ) size [12]. It is recognized that the size of FPZ in rocks is a function, amongst other factors, of the microcrack density in front of a crack tip [12]. On the other hand, the FPZ size influences the measured values of $K_{\text {IC }}$ [12]. Thus, it is possible that the directionally dependent microcrack densities in front of the crack tip may determine distinct values for the measured fracture toughness along the splitting planes.

The practical relevance of the obtained results was illustrated by the use of an existing analytical solution to a crack propagation problem simulating the process of rock cutting/fragmentation through the application of internal pressures on aligned boreholes. The results showed a considerable increase in borehole spacing in case the boreholes are made aligned with the rift plane, the one of least resistance as compared to when the boreholes are aligned with the divider, the plane of maximum resistance.

\section{Acknowledgments}

The authors wish to thank Geol. Wilmar T. de Barros from the Geotechnical Control Office of the municipality of Rio de Janeiro (Geo-Rio) for suggesting the present research topic. They wish to thank the Rock Mechanics Laboratory personnel of CENPES-PETROBRAS in Rio de Janeiro for conducting the tests and the Brazilian National Research Council (CNPq) for the financial support of the first author for his graduate program at the Geology Department of Federal University of Rio de Janeiro, Brazil.

\section{References}

[1] Caruso LG, Braga TO. Granites and marbles in the state of S. Paulo. In: Principal mineral deposits in Brazil. Brasília, Brazil: DNPM (National Department of Mineral Production), CPRM; 1991. p. 399-409 [in Portuguese]

[2] Almeida LCR, Marques EAG, Vargas Jr E do A, Barros WT. Characterisation and utilisation of tensile strength and toughness of granitic and gneissic rocks from Rio de Janeiro-A proposal for optimisation of rock blasting processes. Eighth congress of the international association of engineering geology, IAEG, Vancouver, Canada. 1998. p. 351-7.

[3] Barros WT, D’Orsi RN. Blasting of rock blocks using black powder: an economic solution for slope stabilization. Brazilian conference of engineering geology. $6^{\circ}$ CBGE, November, 1990, Salvador, Brazil [in Portuguese].

[4] Barros WT, Gomes GL. Elimination of geotechnical risks by means of blasting. First Brazilian symposium of rock mechanics. November, 1994, Foz do Iguaçu, Brazil. p. 255-62 [in Portuguese].

[5] Chen Y, Nishiyama T, Kusuda H, Kita H, Sato T. Correlation between microcrack distribution patterns and granitic rock splitting planes. Int J Rock Mech Min Sci Geomech Abstr 1999;36:535-41.

[6] Silva LC. The Geology of the state of Rio de Janeiro. 2nd ed. Brasilia, Brazil: CPRM (Research Center of Mineral Resources); 2001.

[7] ISRM. Determining mode I fracture toughness: suggested method for determining mode I fracture toughness using cracked chevron notched Brazilian disc (CCNBD) specimens. Int J Rock Mech Min Sci Geomech Abstr 1995;32:57-64.

[8] Wang QZ, Jia XM, Wu LZ. Wide-range stress intensity factors for the ISRM suggested method using CCNBD specimens for rock fracture toughness tests. Int J Rock Mech Min Sci 2004;41: 709-16.

[9] Wang QZ, Jia XM, Kou SQ, Zhang ZX, Lindqvist PA. More accurate stress intensity factor derived by finite element analysis for the ISRM suggested rock fracture toughness specimen CCNBD. Int J Rock Mech Min Sci 2003;40:233-41.

[10] Chang S, Lee C, Jeon S. Measurement of rock fracture under modes I and II and mixed-mode conditions by using disc-type specimens. Eng Geol 2002;66:79-97.

[11] Albuquerque MCF, Bortollucci AA, Souza BO. Fracture toughness for some Brazilian rocks. Design and construction in mining, petroleum and civil engineering. Sao Paulo, Brazil. 1998. p. 21-7.

[12] Whittaker BN, Singh RN, Sun G. Rock fracture mechanicsPrinciples, design and applications-Developments in geotechnical engineering, vol. 71. Amsterdam: Elsevier Science Publishers; 1992 $568 \mathrm{p}$.

[13] Kudo Y, Hashimoto K, Sano O, Nakagawa K. Relation between physical anisotropy and microstructures of granitic rock in Japan. In: Proceedings of the sixth international congress of the international society of rock mechanics. Montreal, Canada. 1987. p. 429-32. 
[14] Nasseri MHB, Mohanty B, Robin PYF. Characterization of microstructures and fracture toughness in five granitic rocks. Int $\mathbf{J}$ Rock Mech Min Sci 2005;42:450-60.

[15] Douglass PM, Voight B. Anisotropy of granites: a reflection of microscopic fabric. Geotechnique 1969;19:376-98.

[16] Sih GC. Handbook of stress intensity factors - for researchers and engineers. Bethlehem, Pennsylvania: Institute of Fracture and Solid Mechanics, Lehigh University; 1973 800pp.

[17] Ouchterlony F. Fracture mechanics applied to rock blasting. In: Proceedings of the third congress of the international society of rock mechanics, vol. 2B. ISRM, Denver. 1974. p. 1377-83.
[18] Takemura T, Golshani A, Oda M, Suzuki K. Preferred orientations of open microcracks in granite and their relation with anisotrpic elasticity. Int J Rock Mech Min Sci 2003;40:443-54.

[19] Prikryl R. Some microstructural aspects of strength variation in rocks. Int J Rock Mech Min Sci 2001;38:671-82.

[20] Johnson AM. Physical processes in geology. New York: Freeman, Cooper \& Co.; 1970 577pp.

[21] Dyskin AV, Germanovich LN, Ustinov KV. Asymptotic analysis of crack interaction with free boundary. Int J Solids Struct 2000;37: $857-86$. 